\title{
Preface: advances in cichlid research III: behavior, ecology, and evolutionary biology
}

\author{
Stephan Koblmüller (D) R. Craig Albertson • Martin J. Genner • \\ Kristina M. Sefc • Tetsumi Takahashi
}

Received: 23 January 2019/ Accepted: 30 January 2019/Published online: 11 February 2019

(C) Springer Nature Switzerland AG 2019

The hyperdiverse freshwater fish family Cichlidae accounts for approximately $10 \%$ of today's teleost diversity. For decades, researchers have been thrilled by their enormous diversity in morphology, behavior, and ecology, and by the stunning speciation rates in their adaptive radiations (e.g., Boulenger, 1898; Kosswig, 1947; Fryer, 1960). Today, cichlids are undisputedly among the prime model systems in evolutionary biology research (e.g., Salzburger, 2018).

Guest editors: S. Koblmüller, R. C. Albertson, M. J. Genner, K. M. Sefc \& T. Takahashi / Advances in Cichlid Research III: Behavior, Ecology and Evolutionary Biology

S. Koblmüller $(\square) \cdot$ K. M. Sefc

Institute of Biology, University of Graz, Universitätsplatz

2, 8010 Graz, Austria

e-mail: stephan.koblmueller@uni-graz.at

R. C. Albertson

Department of Biology, University of Massachusetts,

Amherst, MA, USA

M. J. Genner

School of Biological Sciences, Life Sciences Building, 24

Tyndall Avenue, Bristol BS8 1TQ, UK

T. Takahashi

Institute of Natural and Environmental Sciences,

University of Hyogo, Yayoigaoka 6, Sanda,

Hyogo 669-1546, Japan
The current special issue is the third in a series of special issues published in Hydrobiologia exclusively devoted to cichlid research and presents a collection of 22 papers that focus on various aspects of cichlid behavior, ecology, conservation, evolutionary biology, and genomics. Together, they advance our knowledge of the mechanisms generating and maintaining the tremendous diversity within this freshwater fish family. Below, the papers are briefly summarized in the order in which they appear in this special issue.

\section{Time scale of cichlid diversification}

The timescale of cichlid evolution has proven difficult to determine, as molecular phylogenies calibrated by biogeographic and fossil calibrations have often generated strongly contrasting results. Did American and African cichlid fishes diverge when the continents separated 100 million years ago, or did cichlid fishes disperse across the Atlantic at a later date? Matschiner (2019) reviewed the datasets and phylogenetic approaches that have been used to investigate this issue, and conducted re-analyses using more contemporary approaches. Matschiner concludes that the most likely timescale of divergence between American and African cichlids would be 75-60 million years ago and therefore that one or more marine dispersal events must have taken place. 
Generally, one major problem that hampers robust divergence time inference in cichlids is the sparsity of fossils that can be used to calibrate time-trees. Any new reliably identified and dated fossils are more than welcome by cichlid researchers in their struggle to put cichlid diversification in a temporal context. By describing the thus-far oldest reliably identified haplotilapiine cichlid, $\uparrow$ Rebeccachromis gen. nov. (tentatively placed in the tribe Etiini), from the middle-tolate Miocene (c. 11 MYA) from the Central Kenya Rift, Kevrekidis et al. (2019) provides a robust minimum constraint for the age of haplotilapiine cichlids. In addition, Kevrekidis et al. discuss how extensive volcanic activity in the region might have facilitated the evolution of haplotilapiine cichlids.

\section{East African Great Lakes}

The East African Great Lakes are known for their extremely species-rich and largely endemic cichlid species assemblages. Lake Tanganyika is the deepest and oldest of these lakes and harbors the genetically, eco-morphologically and behaviorally most diverse cichlid species assemblage, even though the number of recognized species for Lake Tanganyika is considerably lower than for Lakes Malawi and Victoria (Turner et al., 2001; Koblmüller et al., 2008). Among the many eco-morphological convergences across lakes (Kocher et al., 1993; Santos \& Salzburger, 2012), feeding on scales of other fish is certainly among the most peculiar ones. Even though scaleeating species are also found in other lakes (Fryer \& Iles, 1972), their diversity is the highest in Lake Tanganyika. There, they show varying degrees of dependence on scales for food (Takahashi et al., 2007), with Perissodus micolepis being the most specialized scale eater, exclusively feeding on scales. This highly specialized feeding behavior goes along with a clear left-right head asymmetry that has become a textbook example of balanced polymorphism. Raffini \& Meyer (2019) provide a comprehensive review of the genetics, development, and adaptive significance of head asymmetries in P. microlepis. This review is timely, as the publication of partially contradictory results over the past $10+$ years has complicated our understanding of this system. The authors reviewed this body of literature, which includes evidence for both genetic and nongenetic sources of skull/jaw asymmetries, and provides a roadmap for future studies in this fascinating yet complex system. Scale eaters were also studied empirically for this special issue. Based on morphological assessment and partial sequences of the mitochondrial ND2 gene of ingested scales, Kovac et al. (2019) investigated the prey spectrum of $P$. microlepis in southern Lake Tanganyika. They found that larger fish take larger scales and that $P$. microlepis feeds on a wide prey range that reflects the typical cichlid communities in the lake's rocky littoral zone, indicating that $P$. microlepis is an opportunistic feeder.

Another niche that is occupied by cichlids in all East African Great Lakes is that of pelagic piscivores (Witte \& van Oijen, 1990; Coulter, 1991; Turner et al., 2002). Little is known about their population genetic and phylogeographic structure. Previous work on large (bentho-)pelagic piscivores from Lakes Malawi and Tanganyika revealed a lack of phylogeographic structure on lakewide scales (Genner et al., 2008; Koblmüller et al., 2015), leading to the expectation that this might be true for all highly mobile large eupelagic and benthopelagic predators in these lakes. Koblmüller et al. (2019) tested this hypothesis in four deepwater species of the tribe Bathybatini from Lake Tanganyika. They found that only eupelagic species show panmixis on a lakewide scale, whereas a clear phylogeographic structure was detected in benthopelagic species, and they propose that different predatory niches (i.e., preferred prey species) are responsible for differences in patterns of genetic diversity between eupelagic and benthopelagic species.

Paedophagous cichlids sensu stricto, i.e., species that exploit the buccal phase of mouthbrooding by ramming the heads of mouthbrooding females and feeding on the then-released eggs or larvae, are only found among the haplochromine cichlids from Lake Malawi and the Lake Victoria region, but are absent from Lake Tanganyika. Thus far, only very few species have been reported to show this peculiar behavior. Vranken et al. (2019) focused on the paedophagous cichlids from Lake Edward, a thus-far understudied Great Lake of the Upper Nile region. In general, the taxonomy of cichlid fish endemic to the Lake Edward system is still immature, but even if the total number of cichlid species in this lake is still unknown, it is clearly smaller than in the larger and more intensively studied Lakes Tanganyika, Malawi, and Victoria (Turner et al., 2001). In their study, 
Vranken et al. (2019) provide evidence for five paedophagous cichlids in Lake Edward, three of which are new to science and formally described.

In all East African Great Lakes, the diversity of cichlid species is the highest in the rocky littoral zone, which is not surprising as many of the species are highly stenotopic rock-dwellers for which already very minor stretches of unfavorable habitat might pose significant barriers to gene flow (Rico \& Turner, 2002; Sefc et al., 2017a), facilitating allopatric diversification. Whether allopatrically distributed populations are subject to diversifying selection has been rarely explicitly tested in cichlid populations (Mattersdorfer et al., 2012). Recently, hybridization facilitated by rearrangements of dispersal barriers, for instance, in the wake of lake-level fluctuations, has been suggested to constitute a selection-free pathway to phenotypic diversification (Sefc et al., 2017b). To determine whether population-level differences in phenotype were more likely due to active selection or neutral drift, Husemann et al. (2019) compared patterns of genetic and phenotypic divergences across populations of the Lake Malawi species Maylandia zebra. They focused on traits that are subject to both natural and sexual selection. They found that general levels of phenotypic divergence exceeded those of neutral genetic divergence, which is consistent with diversifying selection as a driver of population-level differences.

Why do some lineages evolve more rapidly or extensively than others? In their article, Albertson \& Pauers (2019) tested a series of hypotheses related to this question using geometric morphometric data in three genera of Lake Malawi rock-dwelling cichlids. They found that levels of morphological disparity, a measure of realized evolutionary potential, did not differ between ecologically diverse and constrained lineages. Rather, disparity was found to be three times higher in species with lakewide versus more limited distributions. This work underscores the complex interplay between ecology and phylogeny in shaping patterns and levels of morphological variation.

Parasites are increasingly recognized as an important factor for shaping patterns of diversification of their hosts (Morand, 2015; Betts et al., 2018). However, to what extent parasites have shaped cichlid adaptive radiations is still largely unknown. Meyer et al. (2019) explored the potential role of parasites for the cichlid radiation in Lake Tanganyika. In a phylogenetically controlled analysis, they compared metazoan parasite infection levels, genetic diversity at the major histocompatibility complex (MHC; important in vertebrate immunity), trophic ecology, and morphology among tribes. Indeed, significant proportions of the variation in parasite abundance and MHC variation are explained by morphology and trophic ecology, respectively. These findings imply that parasites and immunogenetic adaptation might be more important for cichlid diversification than previously assumed.

In addition to highly complex social behaviors and diverse morphologies, cichlid fishes exhibit a striking variation in body coloration. A large amount of previous work have identified numerous selective forces involved in origin and divergence of cichlid body coloration, but we are still far from understanding the genomic, transcriptomic, and physiological bases of color diversity in cichlids (Maan \& Sefc, 2013). Border et al. (2019) investigated the physiological mechanisms regulating body color change from blue to yellow in males of Astatotilapia burtoni, a species distributed in the lower reaches of tributaries to Lake Tanganyika and in the lake proper close to river mouths. In their study, evidence for a role of the melanocortin system comes from the observation that administration of $\alpha$-melanocyte-stimulating hormone increased yellowness of the body due to pigment dispersion of the xanthophores. In contrast, social stress did not influence the expression of color phenotype. Intraspecific color variation was also the focus of the study by Takahashi (2019), who examined the ultimate causes for pale and dark coloration of the shell-breeding Telmatochromis temporalis. Based on data about habitat use, the visual anti-predator adaptation of the dark individuals was attributed to pattern matching, i.e., mingling of dark fish with the shadows of shells, rather than crypsis in the darkness within shells, while pale fish tend to prefer sandy bottoms.

Competition among siblings for limited resources, particularly food provided by parents, is usually nonviolent, but aggression between siblings does occur in some species (Mock \& Parker, 1997; Roulin $\&$ Dreiss, 2012). So far, no studies are available that target the effect of food availability on sibling aggression in species without parental provisioning. Satoh et al. (2019) used field observations and experiments to monitor the dynamics of aggression among siblings in broods of Neolamprologus furcifer, 
a substrate-breeding Lake Tanganyika cichlid species, in relation to age-dependent food type, hunger level, and food availability. Although the study is the first to address sibling aggression in species without parental provisioning, even human parents may gain hope from the distinct effect of increased food supplies on domestic peace.

\section{East African rivers and crater lakes}

For decades, much of the research on African cichlid fishes has focused on the species-rich assemblages in the Great Lakes, and only recently the cichlid faunas of rivers and smaller lakes have received increasing attention (e.g., Stelkens \& Seehausen, 2009; Hermann et al., 2011; Egger et al., 2015; Malinsky et al., 2015; Decru et al.; 2017; Moser et al., 2018). It emerges that the cichlid diversity and degrees of endemism in these water bodies are much higher than previously assumed (e.g., Koblmüller et al., 2012; Genner et al., 2015; Schedel et al., 2018).

A growing concern for freshwater ecologists and evolutionary biologists is the threat to river and small lake biodiversity from invasive species. Native oreochromine cichlids in particular are vulnerable to hybridization with invasive tilapia (Deines et al., 2014; Shechonge et al., 2018) as they are distributed around Africa for aquaculture and attempt to improve fisheries yields. In this issue, Shechonge et al. (2019) report unexpectedly broad distributions of the invasive Nile tilapia (Oreochromis niloticus) and blue-spotted tilapia (Oreochromis leucostictus) in Tanzania and clarify the distributions of native species. To quantify the extent of hybridization among invasive and indigenous oreochromines, Bradbeer et al. (2019) studied Oreochromis communities in the Lake Victoria and Pangani catchments of northern Tanzania using microsatellites and geometric morphometrics. They found that hybrids were relatively rare at their study sites, compared to purebreds, implying that assortative mating dominates in these habitats. This contrasts with other results showing the formation of Oreochromis hybrid swarms at other locations in Tanzania where invasive oreochromines have been introduced (Shechonge et al. 2018), suggesting that the outcome of introduction is not necessarily straightforward to predict. One of the more geographically restricted cichlids in East Africa is Oreochromis hunteri. This species is endemic to Lake Chala- a crater lake that straddles the border between Tanzania and Kenya. This issue features two papers that describe parallel research on the diversity of Oreochromis species in the lake. Both papers show the morphological and molecular (mtDNA) distinction between the $O$. hunter $i$ and a more recently introduced species, referred to as "Bandia" in Dieleman et al. (2019) and $O$. sp. "blue head" in Moser et al. (2019). Both papers use mtDNA to demonstrate that while $O$. hunteri is closely related to species in the neighboring Pangani catchment (e.g., Oreochromis jipe), the more recently introduced species is closely related to $O$. urolepis which is naturally distributed in coastal rivers far southeast of Lake Chala. Collectively, the evidence is suggestive of $O$. urolepis being introduced into Lake Chala. Moser et al. (2019) are concerned that this introduced species, which is now the numerically dominant Oreochromis in the lake, will outcompete the Critically Endangered $O$. hunteri for shared resources and precipitate its extinction.

Crater lake cichlid assemblages are particularly useful for studying evolutionary diversification because of the strong likelihood that diversification of sister taxa has taken place within the lake itself. Lemoine et al. (2019) studied an apparent case of early-stage speciation between two haplochromine cichlids in Lake Saka, a relatively shallow small crater lake in Uganda. Here, male fish have either yellow or blue breeding color, and the two color morphs show subtle levels of genetic differentiation at neutral microsatellite markers, as well as different microhabitat preferences. The authors conclude that speciation may be driven by divergent selection acting on male color in the different habitats.

\section{South America}

Unlike in Africa, where most of the cichlid diversity is found in lakes, South American cichlids mainly diversified in riverine environments, with several examples of adaptive radiations (e.g., Burress et al., 2018a, b). More than half of the South American cichlid species occur in the Amazon Basin (Kullander, 2003), and many of these species are popular aquarium fish. Yet, their taxonomy is complex and poorly resolved, and identifying these fish to species level is often impossible for nonexperts. To overcome this 
issue, DNA barcoding (Hebert et al., 2003) might be a rapid and effective approach to identify Amazonian cichlids to species level. Carvalho et al. (2019) generated DNA barcode reference data for 56 Amazonian cichlid morpho-species. They found that the species/lineage diversity is geographically structured and that the current species diversity in the Amazon basin is drastically underestimated. They further show that for some genera, DNA barcoding is not suitable for reliable species identification because of recent divergence and/or hybridization.

The Paraná and Uruguay rivers constitute the second largest drainage in South America, harboring a tremendous diversity of fishes. Three contributions to this Special Issue target the species diversity of two cichlid genera in this system (Piálek et al., 2019a, b; Říčan et al., 2019). Using phylogeographic and traditional morphological approaches, Říčan et al. (2019) found that the Middle Paraná harbors a higher diversity of endemic Gymnogeophagus species than previously thought. Waterfalls and rapids appear to act as main barriers to dispersal and thus have driven and drive diversification of Gymnogeophagus in this region, a pattern consistent with that found in other cichlid lineages of this region. Piálek et al. (2019a) used a phylogenomic approach combined with mitochondrial data to infer the phylogeny and phylogeography of pike cichlids of the genus Crenicichla in the Middle Paraná system. They found single tributary endemism, parallel evolution of ecomorphs, and strong signatures of (past) introgression among various species. A thus-far undescribed pelagic piscivorous Crenicichla species from the Middle Paraná was shown to be of hybrid origin and described as a new species in Piálek et al. (2019b).

\section{Cichlid sex chromosomes}

How and why sex chromosomes evolve, remain undifferentiated in some taxa and degenerate in others, is a hot topic in evolutionary biology research. Fishes are known for their great variety of different sexdetermining systems. This is particularly true for African cichlid fishes, for which a stunning diversity of sex chromosomes and potential environmental sex determination have been documented (Gammerdinger \& Kocher, 2018; Böhne et al. 2019). Using whole genome data, Gammerdinger et al. (2019) characterized and compared young sex chromosomes across three species of basal haplotilapiine tribes. Their approach confirmed previously reported sexdetermining systems, and identified novel systems. Overall, this work illustrates the utility of the cichlid system for studying the evolution of genetic sex determination and provides a road map for future investigations on the topic.

Taken together, the diverse array of papers presented here furthers our knowledge about the organism-specific and environmental factors, as well as evolutionary processes that have contributed to the outstanding diversity among cichlid fishes. However, this information is not only relevant to this exceptional family of vertebrates. Rather, the messages established by this research have considerable relevance for our general understanding of the evolution of biological diversity. We hope you enjoy reading the contributions.

Acknowledgements We want to thank all the authors for their excellent contributions and all the reviewers for guaranteeing a high scientific standard of the studies published in this special issue. We are particularly thankful to the journal's editor-inchief, Koen Martens, who kindly gave us the opportunity to publish this third cichlid special issue in Hydrobiologia.

\section{References}

Albertson, R. C. \& M. J. Pauers, 2019. Morphological disparity in ecologically diverse versus constrained lineages of Lake Malawi rock-dwelling cichlids. Hydrobiologia, this issue. https://doi.org/10.1007/s10750-018-3829-z.

Betts, A., C. Gray, M. Zelek, R. C. MacLean \& K. C. King, 2018. High parasite diversity accelerates host adaptation and diversification. Science 360: 907-911.

Böhne, S. E., A. A. Weber, J. Rajkov, M. Rechsteiner, A. Riss, B. Egger \& W. Salzburger, 2019. Repeated evolution vs common ancestry: sex chromosome evolution in the haplochromine cichlid Pseudocrenilabrus philander. Genome Biology and Evolution, in press. https://doi.org/10.1093/ gbe/evz003.

Border, S. E., T. J. Piefke, R. J. Fialkowski, M. R. Tryc, T. R. Funnell, G. M. DeOliveira \& P. D. Dijkstra, 2019. Color change and pigmentation in a color polymorphic cichlid fish. Hydrobiologia, this issue. https://doi.org/10.1007/ s10750-018-3755-0.

Boulenger, G. A., 1898. I. Report on the collection of the fishes made by Mr J. E. S. Moore in Lake Tanganyika during his expedition 18895-1896. Transactions of the Zoological Society London 15: 1-30.

Bradbeer, S. J., J. Harrington, H. Watson, A. Warraich, S. Shechonge, A. Smith, R. Tamatamah, B. P. Ngatunga, G. F. Turner \& M. J. Genner, 2019. Limited hybridization 
between introduced and critically endangered indigenous tilapia fishes in northern Tanzania. Hydrobiologia, this issue. https://doi.org/10.1007/s10750-018-3572-5.

Burress, E. D., F. Alda, A. Duarte, M. Loureiro, J. W. Armbruster \& P. Chakrabarty, 2018a. Phylogenomics of pike cichlids (Cichlidae: Crenicichla): the rapid ecological speciation of an incipient species flock. Journal of Evolutionary Biology 31: 14-30.

Burress, E. D., L. Piálek, J. Casciotta, A. Almirón, M. Tan, J. W. Armbruster \& O. Ríčan, 2018b. Island- and lake-like parallel adaptive radiations replicated in rivers. Proceedings of the Royal Society B 285: 20171762.

Carvalho, A. P. C., R. A. Collins, J. G. Martínez, I. P. Farias \& T. Hrbek, 2019. From shallow to deep divergences: mixed messages from Amazon Basin cichlids. Hydrobiologia, this issue. https://doi.org/10.1007/s10750-018-3790-x.

Coulter, G. W., 1991. Lake Tanganyika and Its Life. Oxford University Press, Oxford.

Decru, E., E. Vreven \& J. Snoeks, 2017. The occurrence of an Eastern African haplochromine cichlid in the Ituri River (Aruwimi, Congo basin): adaptive divergence in an introduced species? Hydrobiologia 791: 209-220.

Deines, A. M., I. Bbole, C. Katongo, J. L. Feder \& D. M. Lodge, 2014. Hybridisation between native Oreochromis species and introduced Nile tilapia $O$. niloticus in the Kafue River, Zambia. African Journal of Aquatic Science 39: 23-34.

Dielemann, J., M. Muschick, W. D. Nyingi \& D. Verschuren, 2019. Species integrity and origin of Oreochromis hunteri (Pisces: Cichlidae), endemic to crater Lake Chala (KenyaTanzania). Hydrobiologia, this issue. https://doi.org/10. 1007/s10750-018-3570-7.

Egger, B., Y. Klaefiger, A. Indermaur, S. Koblmüller, A. Theis, S. Egger, T. Näf, M. Van Steenberge, C. Sturmbauer, C. Katongo \& W. Salzburger, 2015. Phylogeographic and phenotypic assessment of a basal haplochromine cichlid fish from Lake Chila, Zambia. Hydrobiologia 748: 171-184.

Fryer, G., 1960. Some controversial aspects of speciation of African cichlid fishes. Journal of Zoology 135: 569-578.

Fryer, G. \& T. D. Iles, 1972. The Cichlid Fishes of the Great Lakes of Africa. T.H.F, Neptune, NJ.

Gammerdinger, W. J. \& T. D. Kocher, 2018. Unusual diversity of sex chromosomes in African cichlid fishes. Genes 9: 480 .

Gammerdinger, W. J., M. A. Conte, B. A. Sandkam, D. J. Penman \& T. D. Kocher, 2019. Characterization of sex chromosomes in three deeply diverged species of Pseudocrenilabrinae (Teleostei: Cichlidae). Hydrobiologia, this issue. https://doi.org/10.1007/s10750-018-3778-6.

Genner, M. J., P. Nichols, P. W. Shaw, G. R. Carvalho, R. L. Robinson \& G. F. Turner, 2008. Genetic homogeneity among breeding grounds and nursery areas of an exploited Lake Malawi cichlid fish. Freshwater Biology 53: 1823-1831.

Genner, M. J., B. Ngatunga, S. Mzighani, A. Smith \& G. F. Turner, 2015. Geographic ancestry of Lake Malawi's cichlid fish diversity. Biology Letters 11: 20150232.

Hebert, P. D. N., A. Cywinska, S. L. Ball \& J. R. deWaard, 2003. Biological identifications through DNA barcodes. Proceedings of the Royal Society London Series B: Biological Sciences 270: 313-321.
Hermann, C. M., K. M. Sefc \& S. Koblmüller, 2011. Ancient origin and recent divergence of a haplochromine cichlid lineage from isolated water bodies in the East African Rift System. Journal of Fish Biology 79: 1356-1369.

Husemann, M., M. Tobler, B. Ding, R. Nguyen, C. McCauley, T. Pilger \& P. D. Danley, 2019. Complex patterns of genetic and phenotypic divergence in populations of the Lake Malawi cichlid Maylandia zebra. Hydrobiologia, this issue. https://doi.org/10.1007/s10750-018-3713-x.

Kevrekidis, C., M. Valtl, S. B. R. Penk, M. Altner \& B. Reichenbacher, 2019. Rebekkachromis nov. gen. from middle-to-upper Miocene (11 MYA) of Central Kenya: the oldest record of a haplotilapiine cichlid fish. Hydrobiologia, this issue. https://doi.org/10.1007/s10750-018-3715-8.

Koblmüller, S., K. M. Sefc \& C. Sturmbauer, 2008. The Lake Tanganyika cichlid species assemblage: recent advances in molecular phylogenetics. Hydrobiologia 615: 5-20.

Koblmüller, S., C. Katongo, H. Phiri \& C. Sturmbauer, 2012. Past connection of the upper reaches of a Lake Tanganyika tributary with the upper Congo drainage suggested by genetic data of riverine cichlid fish. African Zoology 47: 182-186.

Koblmüller, S., E. A. Odhiambo, D. Sinyinza, C. Sturmbauer \& K. M. Sefc, 2015. Big, fish, little divergence: phylogeography of Lake Tanganyika's giant cichlid, Boulengerochromis microlepis. Hydrobiologia 748: 29-38.

Koblmüller, S., L. Zangl, C. Börger, D. Daill, M. P. M. Vanhove, C. Sturmbauer \& K. M. Sefc, 2019. Only true pelagics mix: comparative phylogeography of deepwater bathybatine cichlids from Lake Tanganyika. Hydrobiologia, this issue. https://doi.org/10.1007/s10750-018-3752-3.

Kosswig, C., 1947. Selective mating as a factor for speciation in cichlid fish of East African Lakes. Nature 159: 604-605.

Kullander, S. O., 2003. Family Cichlidae. In Reis, R. E., S. O. Kullander \& C. J. Ferraris (eds), Check List of the Freshwater Fishes of South and Central America. EDIPUCRS, Porto Allegre: 605-654.

Kocher, T. D., J. A. Conroy, K. R. McKaye \& J. R. Stauffer, 1993. Similar morphologies of cichlid fishes in Lakes Tanganyika and Malawi are due to convergence. Molecular Phylogenetics and Evolution 2: 158-165.

Kovac, R., N. Boileau, M. Muschick \& W. Salzburger, 2019. The diverse prey spectrum of the Tanganyikan scale-eater Perissodus microlepis (Boulenger, 1898). Hydrobiologia, this issue. https://doi.org/10.1007/s10750-018-3714-9.

Lemoine, M., M. Barluenga, K. Lucek, S. Mwaiko, M. Haesler, L. J. Chapman, C.A. Chapman \& O. Seehausen, 2019. Recent sympatric speciation involving habitat-associated nuptial colour polymorphism in a crater lake cichlid. Hydrobiologia, this issue. https://doi.org/10.1007/s10750018-3746-1.

Maan, M. E. \& K. M. Sefc, 2013. Colour variation in cichlid fish: developmental mechanisms, selective pressures and evolutionary consequences. Seminars in Cell \& Developmental Biology 24: 516-528.

Malinsky, M., R. J. Challis, A. M. Tyers, S. Schiffels, Y. Terai, B. P. Ngatunga, E. A. Miska, R. Durbin, M. J. Genner \& G. F. Turner, 2015. Genomic islands of speciation separate cichlid ecomorphs in an East African crater lake. Science 350: 1493-1498. 
Matschiner, M., 2019. Gondwanan vicariance or trans-Atlantic dispersal of cichlid fishes: A review of the molecular evidence. Hydrobiologia, this issue. https://doi.org/10.1007/ s10750-018-3686-9.

Mattersdorfer, K., S. Koblmüller \& K. M. Sefc, 2012. AFLP genome scans suggest selection on color patterning in allopatric color morphs of a cichlid fish. Molecular Ecology 21: 3531-3544.

Meyer, B. S., P. I. Hablützel, A. K. Roose, M. J. Hofmann, W. Salzburger \& J. A. M. Raeymaekers, 2019. An exploration of the links between parasites, trophic ecology, morphology, and immunogenetics in the Lake Tanganyika cichlid radiation. Hydrobiologia, this issue. https://doi.org/10. 1007/s10750-018-3798-2.

Mock, D. W. \& G. A. Parker, 1997. The Evolution of Sibling Rivalry. Oxford University Press, Oxford.

Morand, S., 2015. (macro-) Evolutionary ecology of parasite diversity: from determinants of parasite richness to host diversification. International Journal of Parasitology: Parasites and Wildlife 4: 80-87.

Moser, F. N., J. C. van Rijssel, S. Mwaiko, J. I. Meier, B. Ngatunga \& O. Seehausen, 2018. The onset of ecological diversification 50 years after colonization of a crater lake by haplochromine cichlid fishes. Proceedings of the Royal Society B 285: 20180171.

Moser, F. N., J. C. van Rijssel, B. Ngatunga, S. Mwaiko \& O. Seehausen, 2019. The origin and future of an endangered crater lake endemic: phylogeography and ecology of Oreochromis hunteri and its invasive relatives. Hydrobiologia, this issue. https://doi.org/10.1007/s10750-0183780-z.

Piálek, L., E. Burress, K. Dragová, A. Almirón, J. Casciotta \& O. Říčan, 2019a. Phylogenomics of pike cichlids (Cichlidae: Crenicichla) of the $C$. mandelburgeri species complex: rapid ecological speciation in the Iguazú River and high endemism in the Middle Paraná basin. Hydrobiologia, this issue. https://doi.org/10.1007/s10750-018-3733-6.

Piálek, L., J. Casciotta, A. Almirón \& O. Řićan, 2019b. A new pelagic predatory pike cichlid (Teleostei: Cichlidae: Crenicichla) from the C. mandelburgeri species complex with parallel and reticulate evolution. Hydrobiologia, this issue. https://doi.org/10.1007/s10750-018-3754-1.

Raffini, F. \& A. Meyer, 2019. A comprehensive overview of the developmental basis and adaptive significance of a textbook polymorphism: head asymmetry in the cichlid fish Perissodus microlepis. Hydrobiologia, this issue. https:// doi.org/10.1007/s10750-018-3800-z.

Říčan, O., Š. Říčanová, K. Dragová, L. Piálek, A. Almirón \& J. Casciotta, 2019. Species diversity in Gymnogeophagus (Teleostei: Cichlidae) and comparative biogeography of cichlids in the Middle Paraná basin, an emerging hotspot of fish endemism. Hydrobiologia, this issue. https://doi.org/ 10.1007/s10750-018-3691-z.

Rico, C. \& G. F. Turner, 2002. Extreme microallopatric divergence in cichlid species from Lake Malawi. Molecular Ecology 11: 1585-1590.

Roulin, A. \& A. N. Drevis, 2012. Sibling competition and cooperation over parental care. In Nick, J. R., P. T. Smiseth \& M. Kölliker (eds), The Evolution of Parental Care. Oxford University Press, Oxford: 133-149.
Salzburger, W., 2018. Understanding explosive diversification through cichlid fish genomics. Nature Reviews Genetics 19: 705-717.

Santos, M. E. \& W. Salzburger, 2012. How cichlids diversify. Science 338: 619-621.

Satoh, S., K. Ota, S. Awata \& M. Kohda, 2019. Dynamics of sibling aggression of a cichlid fish in Lake Tanganyika. Hydrobiologia, this issue. https://doi.org/10.1007/s10750018-3768-8.

Schedel, F. D. B., E. J. W. M. N. Vreven, B. K. Manda, E. Abwe \& U. K. Schliewen, 2018. Description of five new rheophilic Orthochromis species (Teleostei: Cichlidae) from the Upper Congo drainage in Zambia and the Democratic Republic of Congo. Zootaxa 4461: 301-349.

Sefc, K. M., K. Mattersdorfer, C. M. Hermann \& S. Koblmüller, 2017a. Past lake shore dynamics explain present pattern of unidirectional introgression across a habitat barrier. Hydrobiologia 791: 69-82.

Sefc, K. M., K. Mattersdorfer, A. Ziegelbecker, N. Neuhüttler, O. Steiner, W. Goessler \& S. Koblmüller, 2017b. Shifting barriers and phenotypic diversification by hybridisation. Ecology Letters 20: 651-662.

Shechonge, A., B. P. Ngatunga, R. Tamatamah, S. J. Bradbeer, J. Harrington, A. G. P. Ford, G. F. Turner \& M. J. Genner, 2018. Losing cichlid fish biodiversity: genetic and morphological homogenization of tilapia following colonization by introduced species. Conservation Genetics 19: 1199-1299.

Shechonge, A., B. P. Ngatunga, S. J. Bradbeer, J. J. Day, J. J. Freer, A. G. P. Ford, J. Kihedu, T. Richmond, S. Mzighani, A. M. Smith, E. A. Sweke, R. Tamatamah, A. M. Tyers, G. F. Turner \& M. J. Genner, 2019. Widespread colonization of Tanzanian catchments by introduced Oreochromis tilapia fishes: the legacy from decades of deliberate introduction. Hydrobiologia, this issue. https://doi. org/10.1007/s10750-018-3597-9.

Stelkens, R. B. \& O. Seehausen, 2009. Phenotypic divergence but not genetic distance predicts assortative mating among species of a cichlid fish radiation. Journal of Evolutionary Biology 22: 1679-1694.

Takahashi, R., K. Watanabe, M. Nishida \& M. Hori, 2007. Evolution of feeding specialization in Tanganyika scaleeating cichlids: a molecular phylogenetic approach. BMC Evolutionary Biology 7: 195.

Takahashi, T., 2019. Colour variation of a shell-brooding cichlid fish from Lake Tanganyika. Hydrobiologia, this issue. https://doi.org/10.1007/s10750-018-3717-6.

Turner, G. F., O. Seehausen, M. E. Knight, C. J. Allender \& R. L. Robinson, 2001. How many species of cichlid fishes are there in African lakes? Molecular Ecology 10: 793-806.

Turner, G. F., R. L. Robinson, B. P. Ngatunga, P. W. Shaw \& R. Carvalho, 2002. Pelagic cichlid fishes of Lake Malawi/ Nyasa: biology, management and conservation. In Cowx, I. G. (ed.), Management and Ecology of Lake and Reservoir Fisheries. Blackwell, Oxford: 366-553.

Vranken, N., M. Van Steenberge \& J. Snoeks, 2019. Grasping ecological opportunities: not one but five paedophagous species of Haplochromis (Teleostei: Cichlidae) in the Lake Edward system. Hydrobiologia, this issue. https://doi.org/ 10.1007/s10750-018-3742-5. 
Witte, F. \& M. J. P. van Oijen, 1990. Taxonomy, ecology and fishery of Lake Victoria haplochromine trophic groups. Zoologische Verhandelingen Leiden 262: 1-47.
Publisher's Note Springer Nature remains neutral with regard to jurisdictional claims in published maps and institutional affiliations. 